\title{
Bile Duct Disorder
}

National Cancer Institute

\section{Source}

National Cancer Institute. Bile Duct Disorder. NCI Thesaurus. Code C96716.

A non-neoplastic or neoplastic disorder that affects the intrahepatic or extrahepatic bile ducts. Representative examples of non-neoplastic disorders include cholang itis and biliary atresia. Representative examples of neoplastic disorders include extrahepatic bile duct adenoma and cholangiocarcinoma. 